\title{
In vitro antimicrobial activity of auxiliary chemical substances and natural extracts on Candida albicans and Enterococcus faecalis in root canals
}

\author{
Marcia Carneiro VALERA ${ }^{1}$, Lilian Eiko MAEKAWA ${ }^{2}$, Luciane Dias de OLIVEIRA ${ }^{3}$, Antonio Olavo Cardoso JORGE ${ }^{4}$, \\ Érika SHYGEI ${ }^{5}$, Cláudio Antonio Talge CARVALHO ${ }^{6}$
}

\begin{abstract}
1- DDS, MSc, PhD, Chair Professor, Restorative Dentistry Department, Univ. Estadual Paulista - UNESP, São José dos Campos, São Paulo, SP, Brazil. 2- DDS, MSc, PhD, Restorative Dentistry Department, Univ. Estadual Paulista - UNESP, São José dos Campos, São Paulo, SP, Brazil.

3- DDS, MSc, PhD, Assistant Professor, Biosciences and Oral Diagnosis Department, Univ. Estadual Paulista - UNESP, São José dos Campos, São Paulo, SP, Brazil.

4- DDS, MSc, PhD, Chair Professor, Oral Diagnosis and Biosciences Department, Univ. Estadual Paulista - UNESP, São José dos Campos, São Paulo, SP, Brazil. 5- DDS, School of Dentistry of São José dos Campos, Univ. Estadual Paulista - UNESP, São José dos Campos, São Paulo, SP, Brazil.

6- DDS, MSc, PhD, Associate Professor, Restorative Dentistry Department, Univ. Estadual Paulista - UNESP, São José dos Campos, São Paulo, SP, Brazil.
\end{abstract}

Corresponding address: Marcia Carneiro Valera - Engenheiro Francisco José Longo, 777 - Jd. São Dimas - $12245-000$ - São José dos Campos - SP - Brazil - Phone: (55) 12-3947-9050/12-3947-9048 - Fax: (55) 12-3947-9010 - e-mail: marcia@fosjc.unesp.br

Received: February 14, 2012 - Modification: January 9, 2013 - Accepted: February 7, 2013

\section{ABSTRACT}

\begin{abstract}
$\mathrm{O}$ bjective: The aim of this study was to evaluate the antimicrobial activity of auxiliary chemical substances and natural extracts on Candida albicans and Enterococcus faecalis inoculated in root canals. Material and Methods: Seventy-two human tooth roots were contaminated with $C$. albicans and $E$. faecalis for 21 days. The groups were divided according to the auxiliary chemical substance into: G1) $2.5 \%$ sodium hypochlorite ( $\mathrm{NaOCl}$ ), G2) $2 \%$ chlorhexidine gel (CHX), G3) castor oil, G4) glycolic Aloe vera extract, G5) glycolic ginger extract, and G6) sterile saline (control). The samples of the root canal were collected at different intervals: confirmation collection, at 21 days after contamination; $1^{\text {st }}$ collection, after instrumentation; and $2^{\text {nd }}$ collection, seven days after instrumentation. Microbiological samples were grown in culture medium and incubated at $37^{\circ} \mathrm{C}$ for 48 hours. Results: The results were submitted to the Kruskal-Wallis and Dunn (5\%) statistical tests. $\mathrm{NaOCl}$ and $\mathrm{CHX}$ completely eliminated the microorganisms of the root canals. Castor oil and ginger significantly reduced the number of CFU of the tested bacteria. Reduction of CFU/mL at the $1^{\text {st }}$ and $2^{\text {nd }}$ collections for groups G1, G2, G3 and G4 was greater in comparison to groups G5 and G6. Conclusion: It was concluded that $2.5 \%$ sodium hypochlorite and $2 \%$ chlorhexidine gel were more effective in eliminating C. albicans and $E$. faecalis, followed by the castor oil and glycolic ginger extract. The Aloe vera extract showed no antimicrobial activity.
\end{abstract}

Key words: Ricinus communis. Aloe vera. Zingiber officinale. Sodium hypochlorite. Chlorhexidine.

\section{INTRODUCTION}

Micro-organisms activity and their metabolic products have been reported as being part of the etiology of pulp and periapical lesions, which can certainly lead to pulp necrosis and inflammatory reactions. Root canal infections can be caused by a combination of microorganisms ${ }^{24}$. Enterococcus faecalis has been frequently isolated from infected pulp and persistent infections in post-endodontic treatment ${ }^{24}$. This type of microorganism has the ability to penetrate into the dentinal tubules and survive in root canals without other bacterial support ${ }^{16}$. Its eradication depends on a high $\mathrm{pH}$ value environment $(\mathrm{pH}=11)^{17}$.

A percentage of yeasts, mainly from the Candida genus, ranging from 6 to $55 \%$, can be also found in necrotic pulps ${ }^{20}$. In addition, the presence of Candida spp. in refractory periapical granulomas is reported in studies with a polymerase chain reaction $(P C R)$ analysis ${ }^{21,31}$. Yeasts have been particularly 
associated with persistent root canal infections that did not respond favorably to conservative root canal therapy ${ }^{28}$.

Some properties such as antimicrobial effect, biocompatibility, and ability of tissue dissolving activity are required for irrigating solutions in order to achieve a satisfactory level of cleaning. Sodium hypochlorite has long been recognized as presenting outstanding disinfection properties, and it has been widely used for root canal disinfection ${ }^{19,28,30}$. Amongst its positive properties, sodium hypochlorite is known to be highly irritant to periapical tissues when used at high concentrations ${ }^{22}$.

Chlorhexidine, in liquid or gel formats, has great potential to be used as an endodontic auxiliary chemical substance during the biomechanical preparation. It has shown great efficacy against microorganisms found in root canals $7,8,11,29$. On the other hand, it does not present tissue dissolving activity. For that matter, alternative solutions have been proposed, aiming to associate antimicrobial efficacy, tissue dissolving action and biocompatibility ${ }^{14,26,27}$.

More recently, there have been an increasing number of studies focused on the use of phytotherapic substances for medical purposes. It is known that plant extracts and several types of teas have been used in popular medicine since remote times. However, their real properties and applications have not been scientifically investigated yet. Several companies, groups and developed countries have shown an increasing interest towards the biodiversity of tropical and subtropical countries such as Brazil.

The aim of this study was to evaluate in vitro the antimicrobial activity of auxiliary chemical substances and natural extracts against Candida albicans and Enterococcus faecalis inoculated in root canals.

\section{MATERIAL AND METHODS}

The present study was approved by the Institutional Review Board from Univ. Estadual Paulista - UNESP, São José dos Campos, Brazil (approval n. 093/2005). A total of seventy-two freshly extracted human single-rooted teeth were used in this study. All samples were cleaned and stored in saline prior to use. The crown portion was removed and the length of instrumentation was standardized at $16 \pm 0.5 \mathrm{~mm}$.

The root canals were initially over-instrumented to $0.5 \mathrm{~mm}$ beyond the apex by means of a \#25 K-file (Dentsply Ind. Com. Ltda, Petrópolis, RJ, Brazil), and post-instrumented to $1 \mathrm{~mm}$ from the apex with a \#30 K-file. The root canals were filled with $17 \%$ EDTA solution for 3 minutes and rinsed with $5 \mathrm{~mL}$ of saline solution. The apex was sealed using Z-100 composite resin (3M - Saint Paul, USA) and the roots were externally sealed with epoxy adhesive (Araldite, Brascola, São Paulo, SP, Brazil), except for the cervical opening. All samples were included in transparent light-cured acrylic resin (Dencor Artigos Odontológicos Clássico - São Paulo, SP, Brazil). The specimens were distributed on cell plates (24 wells) (Costar, Corning, New York, USA) and further sterilized by Cobalt-60 gamma radiation ${ }^{6}$.

The microorganisms strains used were Candida albicans (ATCC 18804) and Enterococcus faecalis (ATCC 29212). Both microorganisms were seeded on Petri dishes containing Sabouraud Dextrose Agar (SDA) (Himedia Laboratories, Mumbai, India) for $C$. albicans, and Brain Heart Infusion (BHI) (Himedia Laboratories, Mumbai, India) for E. faecalis. The SDA dishes were incubated in a bacteriological oven at $37 \pm 1^{\circ} \mathrm{C}$ for 24 hours, while the $\mathrm{BHI}$ dishes were incubated for a period of 48 hours.

Standardized saline solution suspensions of $C$. albicans and E. faecalis were prepared ( $10^{8}$ cells/ $\mathrm{mL}$ ) by means of a spectrophotometric technique $(\lambda=530 \mathrm{~nm}, \mathrm{DO}=1.258$, and $\lambda=760 \mathrm{~nm}, \mathrm{DO}=1.258$, respectively). The root canals were contaminated with $10 \mu \mathrm{L}$ of each microorganism suspension and $10 \mu \mathrm{L}$ of BHI broth (Himedia Laboratories, Mumbai, India), resulting in $30 \mu \mathrm{L}$ of inoculated medium in the root canals. A sterile cotton pellet embedded in $\mathrm{BHI}$ broth was placed at the entrance of the canals. The samples were stored in an incubator at $37 \pm 1^{\circ} \mathrm{C}$ in a humid atmosphere for 21 days. During this period, a small amount of BHI broth was placed in the root canals every three days ${ }^{19}$.

After the contamination period, samples of all specimens were collected to confirm the contamination of the root canals (confirmation collection). The samples were then divided into 6 experimental groups $(n=12)$, according to the auxiliary chemical substances used.

Group 1 - 2.5\% sodium hypochlorite solution ( $\mathrm{NaOCl}$ ) (Byofórmula - Farmácia de Manipulação, São José dos Campos, SP, Brazil);

Group 2 - 2\% chlorhexidine gel (Byofórmula Farmácia de Manipulação, São José dos Campos - SP) and irrigation with saline solution between files Exchange;

Group 3 - Castor oil extract (Ricinus communis) (Chemistry Institute of São Carlos - USP, São Carlos, SP, Brazil);

Group 4 - Glycolic ginger extract (Zingiber officinale)(Becker - Farmácia de Manipulação, São José dos Campos, SP, Brazil);

Group 5 - Glycolic Aloe vera extract (Synthon Especialidades Químicas Ltda.);

Group 6 - Sterile saline solution.

The root canals were biomechanically prepared up to a size \#50 K-file and rinsed with $3 \mathrm{~mL}$ of irrigating solution after each file. 
Microbiological samples were collected immediately post-instrumentation ( $1^{\text {st }}$ collection) and seven days post-instrumentation ( $2^{\text {nd }}$ collection).

Root specimens from group 1 were irrigated with $3 \mathrm{~mL}$ of $0.6 \%$ sodium thiosulphate, previous to the first collection, in order to neutralize the remaining $\mathrm{NaOCl}$, while the root canals from group 2 were irrigated with $3 \mathrm{~mL}$ of $0.5 \%$ Tween $80+0.07 \%$ lecithin to neutralize the remaining chlorhexidine ${ }^{19}$.

Each of the three sample collections (confirmation collection, $1^{\text {st }}$ collection, and $2^{\text {nd }}$ collection) was carried out at the same way. A number 30 sterile paper cone (confirmation collection) or a number 50 sterile paper cone ( $1^{\text {st }}$ and $2^{\text {nd }}$ collection) was placed and left in the root canal for one minute. The paper cone was placed in an Eppendorf test tube containing $0.5 \mathrm{~mL}$ sterile saline solution and stirred for 30 seconds. A $0.1 \mathrm{~mL}$ aliquot of each content was seeded and duplicated into dishes containing Agar Sabouraud for C. albicans and Agar Mitis Salivarius for $E$. faecalis.

Subsequent to the first collection, all the root canals were filled with sterile saline solution, and a sterile cotton pellet was placed at the entrance of the canals. The samples were stored in an incubator at $37 \pm 1^{\circ} \mathrm{C}$ with a humid atmosphere for 7 days prior to the second collection.

Characteristic grown colonies of E. faecalis and C. albicans were counted and confirmed by the Gram-color staining method. Descriptive statistics,

Table 1- Colony forming units per $\mathrm{mL}(\mathrm{CFU} / \mathrm{mL})(\log 10)$ for confirmation, first, and second collections

\begin{tabular}{|c|c|c|c|c|c|c|}
\hline \multirow[t]{2}{*}{ Groups } & \multicolumn{2}{|c|}{ Confirmation collection } & \multicolumn{2}{|c|}{$1^{\text {st }}$ collection } & \multicolumn{2}{|c|}{$2^{\text {nd }}$ collection } \\
\hline & C. albicans & E. faecalis & C. albicans & E. faecalis & C. albicans & E. faecalis \\
\hline $\begin{array}{c}\mathrm{G} 1 \\
2.5 \% \mathrm{NaOCl}\end{array}$ & 6.09 & 6.12 & 0 & 0 & 0 & 0 \\
\hline $\begin{array}{c}\mathrm{G} 2 \\
2 \% \mathrm{CLX} \text { gel }\end{array}$ & 6.17 & 6.01 & 0 & 0 & 0 & 0 \\
\hline $\begin{array}{c}\text { G3 } \\
\text { Castor oil }\end{array}$ & 6.16 & 6.24 & 0.50 & 1.57 & 2.80 & 3.49 \\
\hline $\begin{array}{c}\text { G4 } \\
\text { Ginger }\end{array}$ & 6.29 & 8.22 & 0 & 2.42 & 3.50 & 3.49 \\
\hline $\begin{array}{c}\text { G5 } \\
\text { Aloe vera }\end{array}$ & 5.95 & 7.33 & 4.90 & 5.39 & 5.68 & 5.73 \\
\hline $\begin{array}{c}\text { G6 } \\
\text { Saline }\end{array}$ & 6.08 & 6.17 & 4.85 & 5.03 & 5.53 & 5.46 \\
\hline
\end{tabular}

Table 2- Percentage reduction values of $C$. albicans and $E$. faecalis $C F U / m L$, during the first and the second collections in relation to the confirmation collection. The homogeneous groups are also presented

\begin{tabular}{|c|c|c|c|c|c|c|c|c|}
\hline \multirow[t]{3}{*}{ Groups } & \multicolumn{4}{|c|}{ Confirmation $X 1^{\text {st }}$ collection } & \multicolumn{4}{|c|}{ Confirmation $X 2^{\text {nd }}$ collection } \\
\hline & \multicolumn{2}{|c|}{ C. albicans } & \multicolumn{2}{|c|}{ E. faecalis } & \multicolumn{2}{|c|}{ C. albicans } & \multicolumn{2}{|c|}{ E. faecalis } \\
\hline & Median & HG* $^{*}$ & Median & HG* $^{*}$ & Median & HG* & Median & $H^{*}$ \\
\hline $\begin{array}{c}\mathrm{G} 1 \\
\mathrm{NaOCl} \\
2,5 \%\end{array}$ & 100 & $\mathrm{~A}$ & 100 & $A$ & 100 & $A$ & 100 & $A$ \\
\hline $\begin{array}{c}\mathrm{G} 2 \\
2 \% \mathrm{CLX} \text { gel }\end{array}$ & 100 & A & 100 & A & 100 & A & 100 & A \\
\hline $\begin{array}{c}\text { G3 } \\
\text { Castor oil }\end{array}$ & 100 & A & 100 & A & 99.9 & A & 99.9 & A \\
\hline $\begin{array}{c}\text { G4 } \\
\text { Ginger }\end{array}$ & 100 & A & 99.9 & $A B$ & 98.8 & A & 99.9 & A \\
\hline $\begin{array}{c}\text { G5 } \\
\text { Aloe vera }\end{array}$ & 98.5 & B & 98.66 & $\mathrm{BC}$ & 76.7 & B & 77 & B \\
\hline $\begin{array}{c}\text { G6 } \\
\text { Saline }\end{array}$ & 95.1 & B & 93.21 & C & 74.8 & B & 82.6 & B \\
\hline
\end{tabular}

${ }^{*}$ Homogeneous groups: different letters show statistical significant difference $(p<0.05)$ 
and the Kruskal-Wallis test and the Dunn's test (5\%) were used to evaluate the results. The statistical analysis was based on the percentage of reduction.

\section{RESULTS}

The mean values of colony forming units per $\mathrm{mL}$ $(\mathrm{CFU} / \mathrm{mL})$ for each group were determined and are shown in Table 1.

The reduction or complete elimination of $C$. albicans and $E$. faecalis for the first and second collection compared to the confirmation collection, according to the Dunn's test $(5 \%)$, is shown in Table 2.

\section{DISCUSSION}

The root canals within the present study were inoculated with $C$. albicans and E. faecalis for 21 days. The literature shows this contamination period is the reference for obtaining mature biofilms in the dentin ${ }^{2,32}$. Wang, et al. ${ }^{32}$ (2012) evaluated the antibacterial effect of different disinfecting solutions on young and established $E$. faecalis biofilms in dentin canals using a novel dentin infection model. They verified that within the dentin canals, endodontic medications less easily kill bacteria in established biofilms than bacteria in young biofilms.

The results obtained in the present study showed a range of effects against the microorganisms tested, for both the $1^{\text {st }}$ collection and $2^{\text {nd }}$ collection.

The irrigation of the root canals with $2.5 \% \mathrm{NaOCl}$ or $2 \%$ chlorhexidine gel during the instrumentation process, resulted in negative microbiological collections immediately post-instrumentation ( $1^{\text {st }}$ collection) and also for the period of seven days post-instrumentation ( $2^{\text {nd }}$ collection). It shows that those substances are capable of eliminating both E. faecalis and C. albicans. Valera, et al.29,30 (2009, 2010) also assessed $1 \% \mathrm{NaOCl}$ and $2 \%$ clorhexidine gel as significantly reducing the quantity of $C$. albicans and $E$. faecalis inoculated into the root canals.

It is evident that both $2.5 \% \mathrm{NaOCl}$ solution and $2 \%$ chlorhexidine gel have antimicrobial activity and great capacity of penetration into the dentinal tubules, but the efficacy of $\mathrm{NaOCl}$ seven days post biomechanical preparation has not been established by other studies ${ }^{19,28}$. In the present study, the residual effect of those substances have not been evaluated, due to the neutralization process performed after the biomechanical preparation: roots irrigated with $2.5 \% \mathrm{NaOCl}$ were neutralized by $3 \mathrm{~mL}$ of a $0.6 \%$ sodium thiosulphate solution; while roots irrigated with $2 \%$ chlorhexidine gel were neutralized by $3 \mathrm{~mL}$ of a $0.5 \%$ Tween $80+0.07 \%$ lecithin ${ }^{19}$. The neutralization process before the microbiological collection was required once some residues from the irrigating solutions might have remained and inhibited the growing process of microorganisms when using culture medium. However, even with the neutralization process it is possible to evaluate whether microorganisms remained in the tubules after the mechanical preparation and, in this study, the biomechanical preparation completely eliminated $C$. albicans and E. faecalis.

The efficacy of $\mathrm{NaOCl}$ as an irrigating solution has been reported by other studies $3,8,19,30$ at different concentrations. Sodium hypochlorite has been capable of promoting biosynthetic cell alterations and phospholipids damage. These properties are related to the formation of chloramines, which interfere with cell metabolism leading to an oxidizing action. As a consequence, irreversible enzymatic inhibition of the sulphidrila present in bacterial enzymes and degradation of fatty acids and lipids are expected ${ }^{8}$. Gomes, et al. ${ }^{11}$ (2001) verified a better performance of chlorhexidine on E. faecalis in comparison to $2.5 \% \mathrm{NaOCl}$.

The efficacy of chlorhexidine has been already reported in previous studies $8,11,19,29$. The antimicrobial activity of chlorhexidine is based on its positively charged molecule that interacts with negatively charged phosphate groups present on the bacterial cell wall, allowing the chlorhexidine molecule to penetrate the bacteria and leading to intracellular toxic effects ${ }^{7-9}$. This substance acts on Gram-positive and Gram-negative microorganisms. Due to its cationic properties, this biguanide is able to connect to hydroxyapatite, dental biofilm, oral mucosa and salivary proteins. When its concentration decreases in the oral environment, this substance is released from those structures. Such a characteristic is called substantivity, and promotes a durable effect to clorhexidine ${ }^{8,9}$. In concentrations ranging from 0.2 to $2 \%$, chlorhexidine presents a wider antimicrobial spectrum, lower toxicity, better diffusion through the dentinal tubules, biocompatibility, and it has been more efficient in removing the smear layer compared to sodium hypochlorite, which makes this substance a good choice for endodontic therapy $7,8,25$.

Castor oil detergent (Ricinus communis) has shown antimicrobial activity and biocompatibility, non-toxic results, detergent properties, which are important requirements for an irrigant solution $4,5,10,15,27$. The literature has reported that irrigation with castor oil extract is capable of removing debris, showing similar results to $1 \%$ $\mathrm{NaOCl}^{18}$. Valera, et al. ${ }^{27}$ (2012) showed a significant decrease in the number of Escherichia coli in the root canals after irrigation with castor oil extract during the biomechanical preparation. These findings suggest that this substance could be utilized in endodontic therapy.

When analyzing the first collection data of the 
present study, it could be verified that castor oil was able to completely eliminate $C$. albicans and it was also able to significantly reduce the amount of $E$. faecalis. On the other hand, in the second collection data, the development of two microorganisms $(0.1 \%)$, especially E. faecalis, demonstrated that this solution is promising for endodontic purposes. However, more studies are required to clarify its antimicrobial activity mechanism.

The medical use of Aloe vera has been supported by its antimicrobial, anti-inflammatory and regenerative properties ${ }^{12}$. Gontijo, et al. ${ }^{12}$ (2013) evaluated in vivo dentine-pulp behaviour of rats after direct pulp capping with Aloe vera. They observed the presence of acute inflammatory infiltrate (light to moderate) in the first day, while for the calcium hydroxide group (positive control), the presence of acute inflammatory infiltrate was severely related to superficial necrosis. Athiban, et al. ${ }^{1}$ (2012) detected the in vitro antimicrobial activity of Aloe vera over E. faecalis, E. coli and Staphylococcus aureus. It was concluded Aloe vera could be effectively used for decontaminating GP points within a short application time. In the present study, Aloe vera did not show antimicrobial efficacy, once it was not able to eliminate all the microorganisms determined in the first sample collection. Moreover, it allowed a growth of microorganisms between the first and second data collection. According to the comparative Dunn's test (5\%), the Aloe vera group showed similar results compared to the saline group.

The use of ginger (Zingiber officinale) has been appreciated since remote times, and it has been widely used in alcoholic drinks, seasonings and in popular medicine. It was verified that this extract was effective in eliminating microorganisms. The antimicrobial activity of the ginger extract on three Gram-negative anaerobes, Porphyromonas gingivalis, Porphyromonas endodontalis and Prevotella intermedia was observed ${ }^{23}$. The effective action of glycolic and alcoholic ginger extract on S. mutans, Staphylococcus aureus, E. coli and C. albicans ${ }^{13}$ were also reported. This fact might contribute to the treatment of some diseases caused by these types of microorganisms present in the oral cavity. The real mechanism of action of the ginger extract has not yet been elucidated in the literature.

In this study, the irrigation of the root canals with glycolic ginger extract resulted in the negative development of $C$. albicans for the first sample collection (immediately post instrumentation). Although a positive increase of $C$. albicans was observed in the second sample collection, no statistical differences were detected. This result suggests that microorganisms situated deeper in the dentinal tubules were not affected by the irrigating agent, and therefore they were able to recolonize the root canal lumen after seven days. Although E. faecalis was not completely eliminated in the first sample collection, the reduction was close to $100 \%$. In the second sample collection, there was an increase in the number of microorganisms in comparison to the first collection, demonstrating no residual effect. In spite of the growth of microorganisms, the results obtained for the ginger group was statistically similar to $2.5 \% \mathrm{NaOCl}$ and $2 \%$ chlorhexidine gel. The present observed antimicrobial effect of the ginger extract may be related to the very low concentration used. Further investigations on higher concentrations of these substances would be necessary to elucidate the action of the ginger over the microorganisms.

The saline solution (control) used in this experiment was the reference for evaluation of the antimicrobial action of the other substances. Due to its absence of antimicrobial effect, it was possible to assume that the physical action of the instrumentation leads to a considerable decrease in the amount of microorganisms in the root canals.

The results obtained in the present study show that phytotherapic substances might be used in the future as alternative irrigating solutions for endodontic treatment, since they are natural products and do not disturb the environment. As previously mentioned, it is important to support further investigations to identify the most suitable concentration of these substances and their effects over other types of microorganisms and their products.

\section{CONCLUSION}

According to the methodology used and the results obtained in this experiment, it could be concluded that: $2.5 \% \mathrm{NaOCl}$ and $2 \%$ chlorhexidine gel were the most effective irrigating solutions against $C$. albicans and $E$. faecalis, for both the first and second sample collections. They were able to completely eliminate the microorganisms from the root canals. Castor oil extract and glycolic ginger extracts were able to significantly decrease the amount of microorganisms, not being able to completely eliminate them 7 days post biomechanical preparation. The Aloe vera natural extract, did not show antimicrobial efficacy with the methodology used.

\section{ACKNOWLEDGMENTS}

This work was supported by the Brazilian agency São Paulo Research Foundation - FAPESP(2006/57207-2, 2006/57206-6 and 1005/60906-7). 


\section{REFERENCES}

1- Athiban PP, Borthakur BJ, Ganesan S, Swathika B. Evaluation of antimicrobial efficacy of Aloe vera and its effectiveness in decontaminating gutta percha cones. J Conserv Dent. 2012;15:246-8.

2- Baca P, Junco P, Arias-Moliz MT, González-Rodríguez MP, FerrerLuque CM. Residual and antimicrobial activity of final irrigation protocols on Enterococcus faecalis biofilm in dentin. J Endod. 2011;37:363-6.

3- Berber VB, Gomes BPFA, Sena ME, Vianna ME, Ferraz CC, Zaia $A A$, et al. Efficacy of various concentrations of $\mathrm{NaOCl}$ and instrumentation techniques in reducing Enterococcus faecalis within the root canals and dentinal tubules. Int Endod J. 2006;39:10-7.

4- Camargo SE, Camargo CHR, Hiller KA, Rode SM, Schweikl H, Schmalz G. Cytotoxicity and genotoxicity of pulp capping materials in two cell lines. Int J Endod. 2009;42:227-37.

5- Camargo SE, Rode SM, Prado RF, Carvalho YR, Camargo $\mathrm{CH}$. Subcutaneous tissue reaction to castor oil bean and calcium hydroxide in rats. J Appl Oral Sci. 2010;18:273-8.

6- Csako G, Elin RJ, Hochstein D, Tsai CH. Physical and biological properties of U.S. standard endotoxin EC after exposure to ionizing radiation. Infect Immun. 1983;41:190-6.

7- Ercan E, Ozekinci T, Atakul F, Gul K. Antibacterial activity of $2 \%$ chlorhexidine gluconate and $5.25 \%$ sodium hypochlorite in infected root canals: in vivo study. J Endod. 2004;30:84-7.

8- Estrela C, Ribeira RG, Estrela CRA, Pécora JD, Sousa Neto MD. Antimicrobial effect of $2 \%$ sodium hypochlorite and $2 \%$ chlorhexidine tested by different methods. Braz Dent J. 2003; 14:58-62.

9- Ferraz CCR, Gomes BPFA, Zaia AA, Teixeira FB, Souza-Filho. In vitro assessment of the antimicrobial action and the mechanical ability of chlorhexidine gel as an endodontic irrigant. J Endod. $2001 ; 27: 452-5$

10- Ferreira CM, Silva Rosa OP, Torres SA, Ferreira FB, Bernardinelli N. Activity of endodontic antibacterial agents against selected anaerobic bacteria. Braz Dent J. 2002;13:118-22.

11- Gomes BPFA, Ferraz CCR, Vianna ME, Berber VB, Teixeira $\mathrm{FB}$, Souza-Filho FJ. In vitro antimicrobial activity of several concentrations of sodium hypochlorite and chlorhexidine gluconate in the elimination of Enterococcus faecalis. Int Endod J. 2001;34:424-8.

12- Gontijo SML, Gomes ADM, Gala-Garcia A, Sinisterra RD, Cortés MD. Evaluation of antimicrobial activity and cell viability of Aloe vera sponges. Eletron J Biotechnol. 2013;16:1-10.

13- Grégio AMT, Fortes ESM, Rosa EAR, Simeone RB, Rosa RT. Antimicrobial activity from Zingiber officinalle on oral cavity pathogens. Estud Biol. 2006;28:61-6.

14- Kuruvilla JR, Kamath MP. Antimicrobial activity of $2.5 \%$ sodium hypochlorite and $0.2 \%$ chlorexidine gluconate separately and combined, as endodontic irrigants. J Endod. 1998;24:472-6. 15- Leonardo MR, Silva LA, Tanomaru M Filho, Bonifácio KC, Ito IY. In vitro evaluation of the antimicrobial activity of a castor oilbased irrigant. J Endod. 2001;27:717-9.

16- Love RM. Enterococcus faecalis - a mechanism for its role in endodontic failure. Int Endod J. 2001;34:341-5.
17- McHugh $\mathrm{CP}$, Zhang $\mathrm{P}$, Michalek S, Eleazer PD. pH required to kill Enterococcus faecalis in vitro. J Endod. 2004;30:218-9.

18- Meneghin MP, Nomelini SM, Sousa-Neto MD, Marchesan MA, França SC, Santos HS. Morphologic and morphometric analysis of the root canal apical third cleaning after biomechanical preparation using 3.3\% Ricinus communis detergent and $1 \% \mathrm{NaOCl}$ as irrigating solutions. J Appl Oral Sci. 2006;14:178-82.

19- Menezes MM, Valera MC, Jorge AOC, Koga-Ito CY, Camargo $\mathrm{CHR}$, Mancini MNG. In vitro evaluation of the effectiveness of irrigants and intracanal medications on microorganisms within the root canals. Int Endod J. 2004;37:311-9.

20- Nair PNR. Intra-radicular bacteria and fungi in root-filled, asymptomatic human teeth with therapy-resistant periapical lesions: along-term light and electron microscope follow-up study. J Endod. 1990;16:580-8.

21- Najzar-Fleger D, Filipovic D, Prpic G, Kobler D. Candida in root canal in accordance with oral ecology. Int Endod J. 1992;25:40. 22- Onçag O, Hosgor M, Hilmioglu S, Zekioglu O, Eronat C, Burhanoglu D. Comparison of antibacterial and toxic effects of various root canal irrigants. Int Endod J. 2003;36:423-32.

23- Park M, Bae J, Lee DS. Antibacterial activity of [10]-gingerol and [12]-gingerol isolated from ginger rhizome against periodontal bacteria. Phytother Res. 2008;22:1446-9.

24- Sakamoto M, Siqueira JF Jr, Rôças IN, Benno Y. Molecular analysis of the root canal microbiota associated with endodontic treatment failures. Oral Microbiol Immunol. 2008;23:275-81.

25- Soares JA, Leonardo MR, Silva LAB, Tanomaru M Filho, Ito IY. Histomicrobiologic aspects of root canal system and periapical lesions in dog's teeth after rotatory instrumentation and intracanal dressing with calcium hydroxide pastes. J Appl Oral Sci. 2006;14:355-64.

26- Valera MC, Rosa JA, Maekawa LE, Oliveira LD, Carvalho CA, Koga-Ito $\mathrm{CY}$, et al. Action of propolis and medications against Escherichia coli and endotoxin in root canals. Oral Surg Oral Med Oral Pathol Oral Radiol Endod. 2010;110:e70-4.

27- Valera MC, Maekawa LE, Chung A, Oliveira LD, Carvalho CA, Koga-Ito CY, et al. Effectiveness of castor oil on Escherichia coli and its endotoxins in root canals. Gen Dent. 2012;60:204-9.

28- Valera MC, Rego JM, Jorge AOC. Effect of sodium hypochlorite and five intracanal medications on Candida albicans in root canals. J Endod. 2001;27:401-8.

29- Valera MC, Salvia AC, Maekawa LE, Camargo SE, Carvalho $\mathrm{CA}$, Camargo $\mathrm{CH}$, et al. Antimicrobial analysis of chlorhexidine gel and intracanal medications against microrganisms inoculated in root canals. Minerva Stomatol. 2010;59:415-21.

30- Valera MC, Silva KC, Maekawa LE, Carvalho CA, Koga-Ito CY, Camargo $\mathrm{CH}$, et al. Antimicrobial activity of sodium hypochlorite associated with intracanal medication for Candida albicans and Enterococcus faecalis inoculated in root canals. J Appl Oral Sci. 2009;17:555-9.

31- Waltimo TM, Kuusinem $M$, Järvensivu $A$, Nyberg $P$, Väänänen $A$, Richardson $M$, et al. Examination on Candida spp. in refractory periapical granulomas. Int Endod J. 2003;36:643-7.

32- Wang Z, Shen Y, Haapasalo M. Effectiveness of endodontic disinfecting solutions against young and old Enterococcus faecalis biofilms in dentin canals. J Endod. 2012;38:1376-9. 